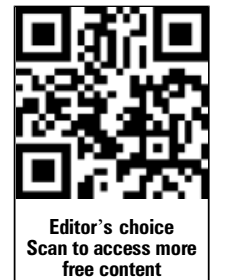

${ }^{1}$ Department of Pathology, Singapore General Hospital, Singapore

${ }^{2}$ Department of

Histopathology, University of Nottingham, Nottingham City Hospital NHS Trust, Nottingham, UK

\section{Correspondence to}

Dr Puay Hoon Tan,

Department of Pathology, Singapore General Hospital, Outram Road, Singapore 169608, Singapore; tan.puay.hoon@sgh.com.sg

Received 25 February 2013 Accepted 26 February 2013 Published Online First 26 March 2013
To cite: Tan $\mathrm{PH}$, Ellis 10. I Clin Pathol 2013;66: 465-470.

\title{
Myoepithelial and epithelial-myoepithelial, mesenchymal and fibroepithelial breast lesions: updates from the WHO Classification of Tumours of the Breast 2012
}

\author{
Puay Hoon Tan, ${ }^{1}$ Ian 0 Ellis ${ }^{2}$
}

\begin{abstract}
In the 4th edition of the WHO Classification of Tumours of the Breast, myoepithelial lesions are retitled myoepithelial and epithelial-myoepithelial lesions in order to better reflect the dual participation of luminal and myoepithelial compartments in some key entities. Malignant myoepithelioma, described as a section within the chapter on myoepithelial lesions in the 3rd edition, is recognised in the 4th edition as part of metaplastic carcinoma. Adenomyoepithelioma with malignancy is categorised in terms of the cellular component undergoing malignant transformation. The list of antibodies that can be used for identifying myoepithelial cells is updated. Among mesenchymal lesions, new additions are nodular fasciitis and atypical vascular lesions, while the haemangiopericytoma is removed. The 3 rd edition stated that pathological prediction of behaviour of phyllodes tumours is difficult in the individual case. In the 4th edition, some progress has been made in prioritisation and weighting of histological parameters that can potentially estimate probability of recurrence. The WHO Working Group advocates leaning towards a diagnosis of fibroadenoma in cases where there is histological uncertainty in distinction from a benign phyllodes tumour, or adopting the neutral term 'benign fibroepithelial neoplasm', as the clinical behaviour of fibroadenoma overlaps with that of benign phyllodes tumour. The 3rd edition terminology of 'periductal stromal sarcoma' is revised to 'periductal stromal tumour', akin to the widespread consensus to avoid the use of the term 'cystosarcoma' in the context of phyllodes tumours.
\end{abstract}

\section{INTRODUCTION}

Classification of breast lesions is an evolving process and a continual work in progress. In the 2003 3rd edition of the WHO Classification of Tumours, taxonomy and nomenclature of breast neoplasms were combined with those of tumours of the female genital tract. ${ }^{1}$ The latest edition of the WHO Classification of Tumours of the Breast published in 2012 is dedicated purely to breast lesions, allowing more detailed description and discussion of the wide spectrum of breast tumours. ${ }^{2}$ The contents encompass contributions from an international panel of breast pathologists, incorporating current knowledge of breast neoplasms, with updates on classification based on improved clinical pathobiological and molecular genetic information.

While the list of breast tumours remains relatively unchanged between the two volumes, some modifications to their arrangement, terminology and groupings have been implemented, reflecting current understanding, practice and consensus.

In this article, updates and revisions to the segments of myoepithelial and epithelial-myoepithelial, mesenchymal and fibroepithelial breast lesions are specifically addressed, including discussions and deliberations of the WHO Working Group that convened in September 2011 in Lyon, France, to agree on the proposed changes.

\section{MYOEPITHELIAL AND EPITHELIAL-MYOEPITHELIAL LESIONS \\ Myoepithelial lesions}

A readily noticeable change to this chapter is the alteration of the previous title of 'myoepithelial lesions' to the current designation of 'myoepithelial and epithelial-myoepithelial lesions' in order to better reflect the dual participation of luminal and myoepithelial compartments in key entities encompassed under the rubric of this group of tumours.

Myoepithelial lesions, defined as those consisting of a pure or predominant myoepithelial cell population, include myoepithelial hyperplasia, collagenous spherulosis and myoepithelial carcinoma.

In the WHO 2003 instalment, myoepitheliosis was a specific entity included in the chapter on myoepithelial lesions. ${ }^{1}$ It was defined as a multifocal, often microscopic proliferation of spindle to cuboidal myoepithelial cells growing into and around small ducts and ductules. Myoepitheliosis was further subdivided into intraductal and periductal varieties, depending on whether myoepithelial cells proliferated into, or around, ducts and ductules, respectively. ${ }^{13} 4$ The Working Group agreed that microscopic nuances to allow consistent and reproducible use of these terminologies were difficult to achieve in diagnostic practice, and unanimously agreed to amalgamate these alterations into the unifying concept of myoepithelial hyperplasia. All those present at the Consensus Conference also admitted to not using the term 'myoepitheliosis' in daily practice.

The lesion of 'adenomyoepithelial adenosis', included as a myoepithelial condition in the 3rd edition, was referred to as an extremely rare type of adenosis associated with adenomyoepithelioma. ${ }^{1}$ In similar fashion to the discussion on myoepitheliosis, the Working Group regarded histological changes described for this lesion as myoepithelial hyperplasia in the context of adenosis. ${ }^{2}$ Hence the alterations of 'myoepitheliosis' and 'adenomyoepithelial adenosis' as originally documented in the previous edition are 
ascribed to the spectrum of myoepithelial hyperplasia in the 2012 volume (figure 1).

While collagenous spherulosis was not officially acknowledged among myoepithelial lesions in the 3rd edition, it is a condition that consists of myoepithelial cells arranged around cribriform spaces filled with pink spherules of basement membrane material. ${ }^{5-13}$ Immunohistochemical staining with myoepithelial markers confirms the myoepithelial origin of cells encircling the rounded spaces. It may be argued whether the characteristic appearance of collagenous spherulosis is due to an interplay of both epithelial and myoepithelial cells and hence technically an epithelial-myoepithelial lesion rather than a solely myoepithelial condition, but the cribriform architecture is contributed by purely myoepithelial cells residing within a duct/ lobular unit that can be affected by a variety of proliferative changes from usual ductal hyperplasia, intraductal papilloma, sclerosing adenosis, lobular neoplasia and adenomyoepithelioma ${ }^{6713}$ (figure 2).

A malignant lesion composed of myoepithelial cells is a myoepithelial carcinoma (malignant myoepithelioma), ${ }^{3}{ }^{14}$ which is classified under metaplastic carcinoma in this 4th edition. ${ }^{2}$ Histologically, it features spindled cells which may be relatively bland, but which exhibit typically both epithelial ${ }^{15}$ and myoepithelial differentiation such as smooth muscle reactivity, immunophenotypically. ${ }^{16}{ }^{17}$ The overlap in microscopic and immunophenotypic characteristics with metaplastic carcinoma is well recognised, making its formal distinction from the latter challenging, ${ }^{18} 19$ and in view of the similar clinical outcome, ${ }^{20} 21$ potentially superfluous. In a purely spindle cell malignant breast tumour with immunohistochemical evidence of keratin and smooth muscle differentiation, a diagnosis of spindle cell metaplastic carcinoma is deemed appropriate. Support for a firm diagnosis of 'myoepithelial' carcinoma ensues from identification of malignant cells emanating from the myoepithelial layer of pre-existing ducts or from the myoepithelial compartment of an epithelialmyoepithelial lesion such as adenomyoepithelioma ${ }^{1622}$ (figure 3).

\section{Epithelial-myoepithelial lesions}

Pleomorphic adenoma of the breast is a benign mixed tumour histologically similar to its salivary gland counterpart. ${ }^{23}{ }^{24}$ It consists of epithelial cells occurring as cohesive and irregular nests and tubules accompanied by dispersed myoepithelial cells immersed in a chondromyxoid matrix (figure 4). In both the

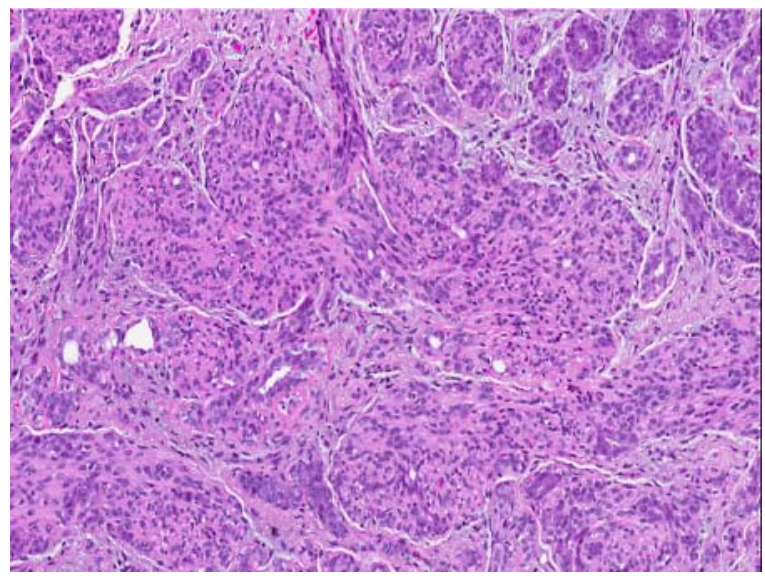

Figure 1 Myoepithelial hyperplasia. Plump, pink, spindled myoepithelial cells swirl around diminutive tubular lumens in an example of sclerosing adenosis.

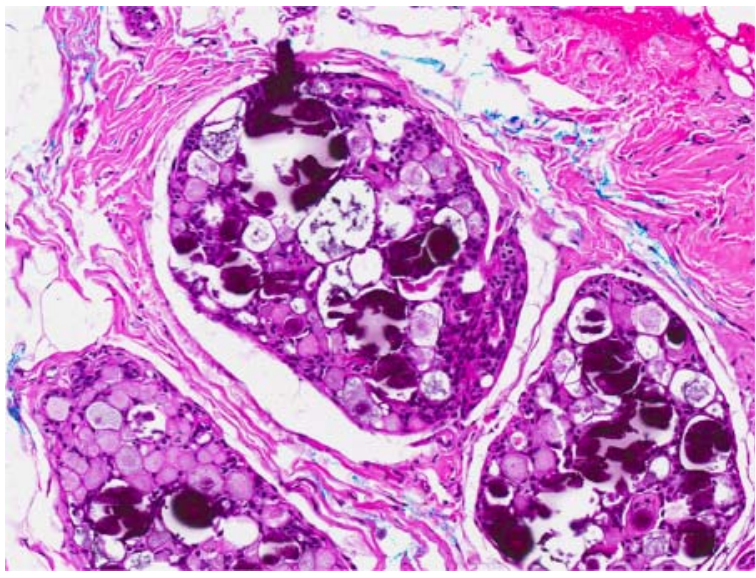

Figure 2 Collagenous spherulosis shows well-defined cribriform spaces containing pink basement membrane material, accompanied by calcifications which can be detected radiologically.

2003 and 2012 volumes, pleomorphic adenoma is described together with other adenomas, but recognition of the dual participation of epithelial and myoepithelial cells is acknowledged in the current edition, with the entity included in the classification of epithelial-myoepithelial tumours.

An adenomyoepithelioma is a stereotypical epithelial-myoepithelial tumour, composed of myoepithelial cells surrounding epithelium lined spaces, giving a histological appearance of a balanced dual proliferation of two cell types ${ }^{25-28}$ (figure 5). Squamous nests with eosinophilic hardened cytoplasm, and sebaceous differentiation with finely vacuolated lipidised cytoplasm, may be seen. ${ }^{29}{ }^{30}$ Either or both epithelial and myoepithelial components can undergo malignant transformation, ${ }^{41-37}$ the latter exemplified by myoepithelial carcinoma arising within the background of an adenomyoepithelioma. Mitoses, cytonuclear atypia and infiltration attest to the malignant nature of the spindle myoepithelial cells. Categorisation of the malignant compartment associated with adenomyoepithelioma differs from the prior edition, with removal of the terms sarcoma and carcinosarcoma in the current volume, since technically, malignancy arising from either component of the adenomyoepithelioma should be considered carcinoma.

Adenoid cystic carcinoma is a unique malignant tumour with an excellent prognosis, despite its often triple negative status, formed by a combination of cells of epithelial and myoepithelial phenotype arranged as cribriform and tubular structures, with production of both watery mucopolysaccharide and viscid basement membrane material ${ }^{38-42}$ (figure 6). Immunohistochemistry shows positive staining for p63 and other myoepithelial markers in lesional cells surrounding these pseudolumens, while luminal type low molecular weight keratins decorate cells rimming true lumens that are also present in adenoid cystic carcinoma, making it a bona fide epithelial-myoepithelial tumour. ${ }^{8} 4344$ Although adenoid cystic carcinoma is detailed together with other invasive breast carcinomas, it is formally classified as an epithelial-myoepithelial tumour in the current edition.

\section{Immunohistochemistry for myoepithelial cells}

The important role of immunohistochemistry in evaluating myoepithelial and epithelial-myoepithelial lesions is addressed and given substantial emphasis in this volume. ${ }^{2}$

A note is made of the wide range of markers available for the detection of myoepithelial differentiation, with variable sensitivities and specificities. ${ }^{45-49}$ There is a range of antibodies to 

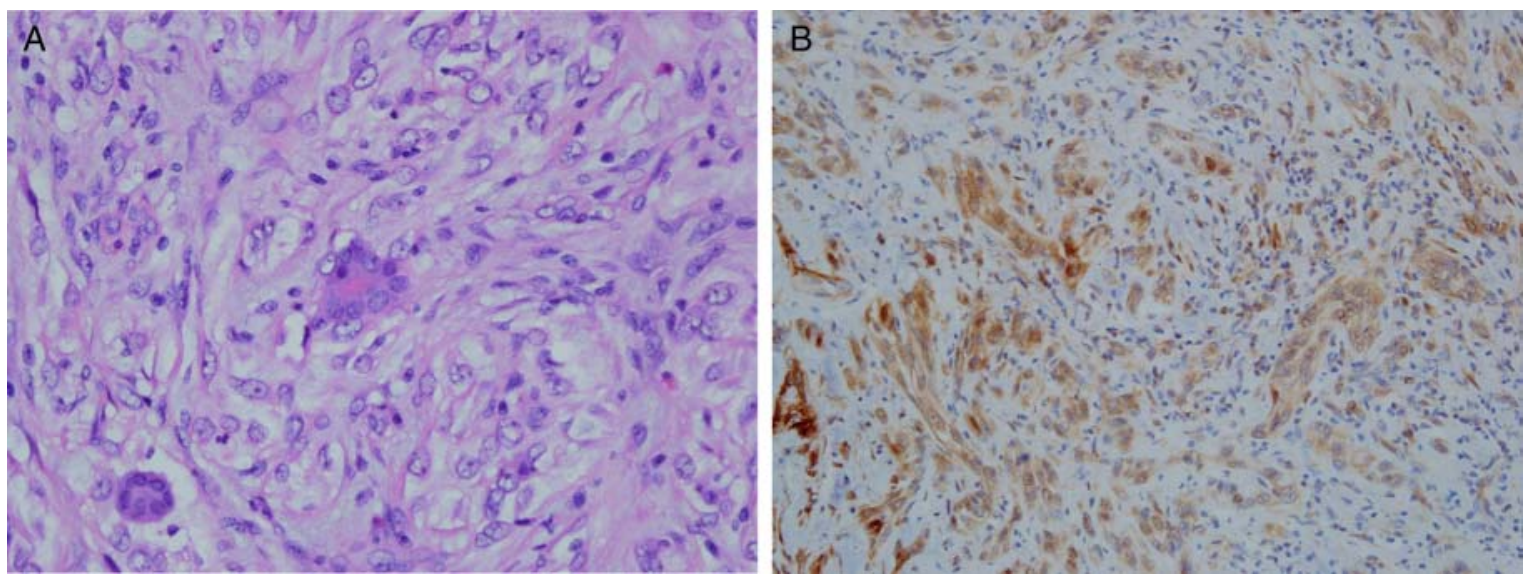

Figure 3 (A) Elongated abnormal spindle cells with enlarged vesicular nuclei of myoepithelial carcinoma appear to originate from the outer contours of tubules of adenomyoepithelioma lined by bland luminal epithelium. (B) Immunohistochemistry for smooth muscle actin shows positive cytoplasmic reactivity of the plump spindle cells that are aggregated into small vague clusters.

high molecular weight keratins that can detect myoepithelial cells, as well as myriad antibodies for illuminating smooth muscle expression in these cells. ${ }^{50-52}$ The potential cross reactivity of smooth muscle antibodies with stromal myofibroblasts is reiterated. ${ }^{50}$ The Working Group recommends a panel approach with use of a minimum of 2-3 antibodies that are well validated, familiar and routinely adopted in the individual laboratory. ${ }^{2}$ For recognition of myoepithelial and metaplastic carcinoma, a broad immunohistochemical panel needs to be applied, including applying antibodies to high molecular weight/basal keratins. 185354

A list of antibodies that can be used in immunohistochemical workup, mirroring that provided in the current 2012 volume, is presented in table $1 .^{2}$

\section{MESENCHYMAL LESIONS}

The group of benign mesenchymal lesions remains largely unchanged from the previous edition, apart from inclusion of the following new entities, nodular fasciitis and atypical vascular lesions, and the deletion of the previously included haemangiopericytoma. ${ }^{2}$

Nodular fasciitis is included in this volume in line with its recognition as a tumour composed of a clonal population of fibroblasts and myofibroblasts ${ }^{55-58}$ (figure 7). A rare tumour, it needs to be

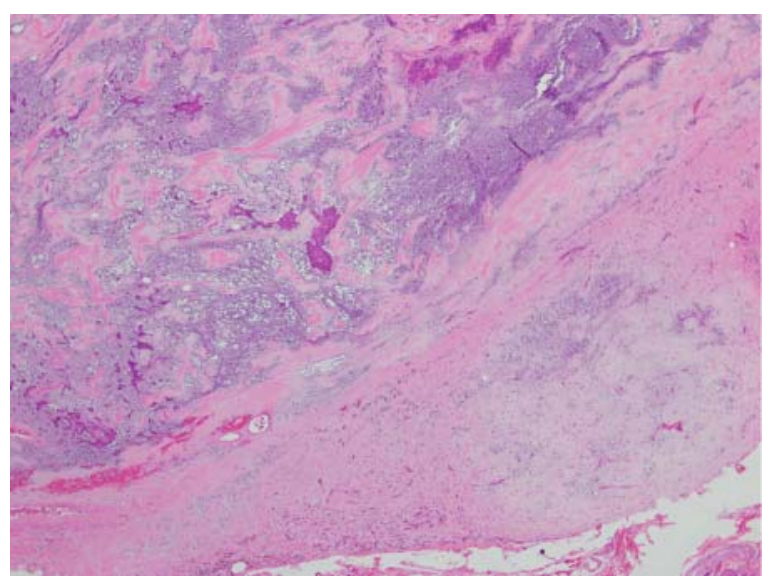

Figure 4 Pleomorphic adenoma of the breast shows a circumscribed boundary at low magnification, with epithelial nests immersed in a chondromyxoid matrix containing spindled myoepithelial cells. distinguished from other spindle cell proliferations such as fibromatosis, low-grade spindle cell metaplastic carcinoma, low-grade myxofibrosarcoma ${ }^{59}$ and stromal overgrowth of phyllodes tumours.

The atypical vascular lesion was not part of the last WHO edition. ${ }^{1}$ However, these angioformative proliferations are sometimes encountered in the skin after breast conserving surgery and radiotherapy for breast carcinoma, and may represent the precursor to angiosarcoma. ${ }^{26-63}$ Histologically, atypical vascular lesions have to be discriminated from low grade or well-differentiated angiosarcoma, with the latter revealing vascular channels that dissect intrusively into the skin and/or breast parenchyma, accompanied by variable endothelial atypia and free floating endothelium coated scaffolds.

Notwithstanding its alteration in nosology to solitary fibrous tumour in the soft tissue arena, the haemangioperictyoma has been deleted in the current edition as it is vanishingly rare in the breast. ${ }^{1} 264$ There was some discussion on the purported relationship of the solitary fibrous tumour (previously referred to as haemangiopericytoma) with myofibroblastoma and the spindle cell lipoma, ${ }^{65}$ but apart from the debate and controversy on whether there is a real association of these lesions, its exceptional discovery in the breast resulted in its exclusion.

The remaining benign and malignant mesenchymal lesions have been updated in content.

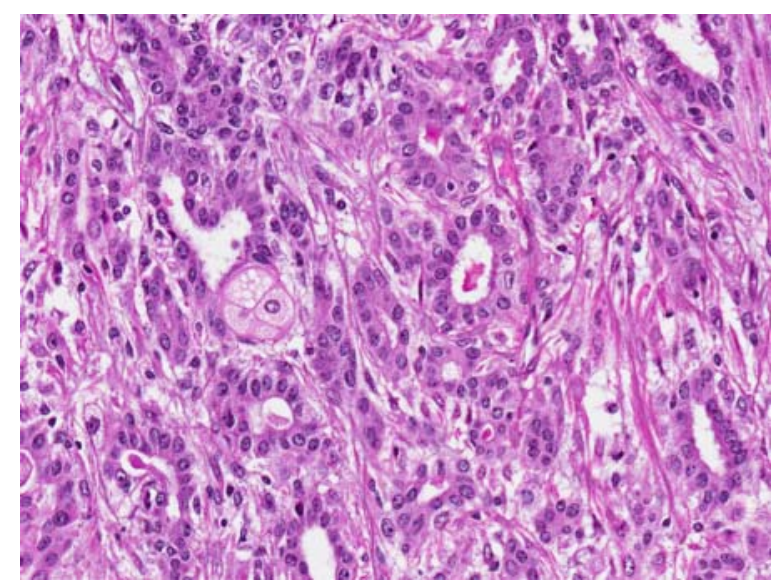

Figure 5 High magnification of an adenomyoepithelioma displays tubules rimmed by prominent myoepithelial cells. Sebaceous metaplasia featuring cells with finely lipidised cytoplasm is present. 


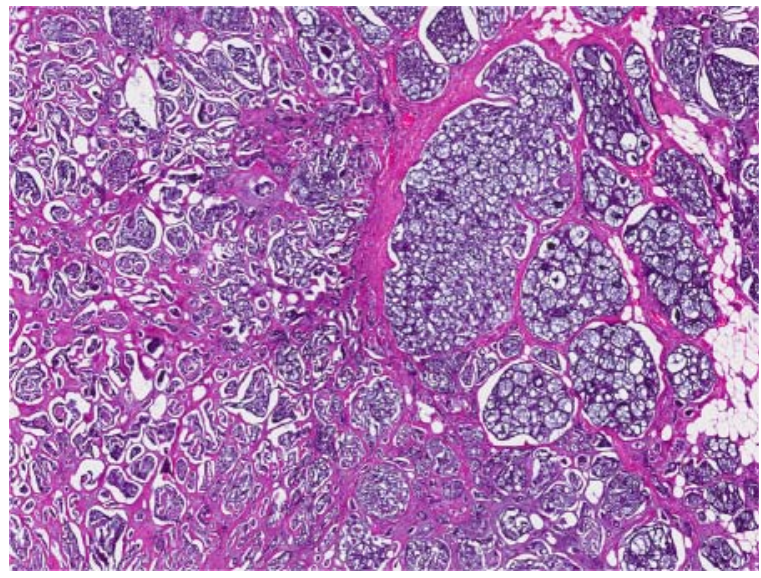

Figure 6 Adenoid cystic carcinoma with the characteristic appearances of cribriform structures containing watery mucopolysaccharide and pink viscid basement membrane material.

In particular, the classification of angiosarcoma of the breast is recapitulated, with specific mention of the lack of prognostic value of grade, as documented in a large study of primary angiosarcoma of the breast. ${ }^{66}$

\section{FIBROEPITHELIAL LESIONS}

Fibroepithelial tumours represent a heterogeneous group of biphasic neoplasms composed of a proliferation of both epithelial and stromal components, with the main occupants being the common fibroadenoma and the rarer phyllodes tumour.

In 2012, this chapter has been updated with regard to histological characterisation and classification. Consistent with discouragement of the use of the historical term 'cystosarcoma' for phyllodes tumours, the Working Group recommended that the exceedingly rare entity of periductal stromal sarcoma (as it was referred to in the previous edition) be revised to the less ominous term, periductal stromal tumour. ${ }^{12}$ The close morphological relationship between the periductal stromal and phyllodes tumours is acknowledged.

The rest of the chapter is devoted to discussion on differential diagnosis of fibroepithelial neoplasms, inherent issues with grading of phyllodes tumours, as well as to the challenges of accurate prediction of recurrent likelihood and clinical behaviour in individual women diagnosed with phyllodes tumours. ${ }^{67}$

At the benign end of the spectrum of fibroepithelial lesions, a diagnostic dilemma arises when faced with a tumour with overlapping features of fibroadenoma and benign phyllodes tumour. ${ }^{68} \mathrm{At}$ the consensus conference, the question of whether there was a

Table 1 Common antibodies that decorate myoepithelial cells

\begin{tabular}{ll}
\hline Myoepithelial cell properties & Antibodies \\
\hline Smooth muscle differentiation & Smooth muscle actin \\
& Muscle specific actin \\
& Calponin \\
& Caldesmon \\
& Smooth muscle myosin heavy chain \\
High molecular weight (basal cell) keratins & CK5 \\
& CK5/6 \\
& CK14 \\
& CK17 \\
& $34 \beta E 12$ \\
Nuclear phosphoprotein/transcription factor & p63 \\
\hline
\end{tabular}

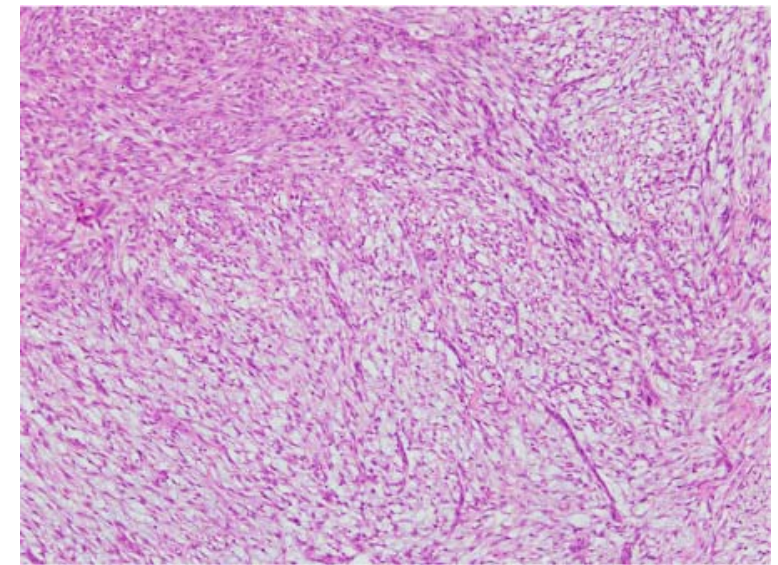

Figure 7 Nodular fasciitis shows intersecting oedematous spindle cell fascicles of fibroblasts and myofibroblasts, giving a feathery, tissue culture-like appearance.

need for precise distinction in every case was discussed and centred around whether there was a difference in risk of recurrent disease and likelihood of malignant progression of a fibroadenoma and a benign phyllodes tumour. Histologically, the characteristics of both lesions are similar, with the benign phyllodes tumour showing an accentuated intracanalicular appearance with leafy fronds accompanied by stromal hypercellularity, often with periepithelial stromal accumulation ${ }^{69}$ (figure 8 ). This contrasts with the fibroadenoma, which has none, few or poorly formed fronds, and is generally without significant stromal cellularity.

While the fibroadenoma is not thought of as being associated with recurrence, there are a few sporadic reports of fibroadenoma recurrences in the range of $15 \%-17 \% .^{70-72}$ This rate is similar to that described for benign phyllodes tumours, which have reported recurrences ranging from $10 \%$ to $17 \% .{ }^{6769} 73 \mathrm{In}$ one series, where a frequency of $10.9 \%$ recurrence was observed in benign phyllodes tumours, and despite the majority of these recurrent lesions remaining benign, 35\% were upgraded to borderline and $8 \%$ to malignant tumours, corresponding to $1 \%$ of originally benign neoplasms recurring as malignant lesions. ${ }^{67}$ In other words, while the overall recurrence rates of benign phyllodes tumours are comparable with fibroadenomas, suggesting a similar outcome, the critical difference is that a small percentage of phyllodes tumours may recur as malignant lesions. At present, there are no known identifiable characteristics which

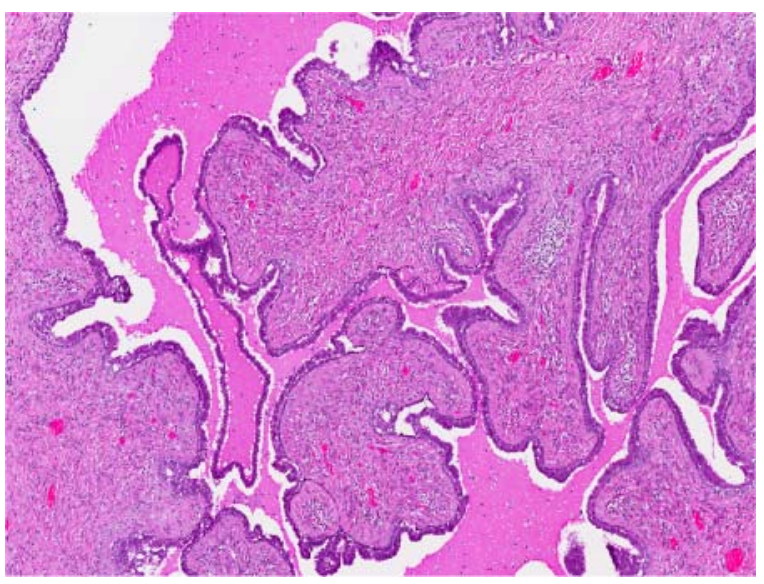

Figure 8 A benign phyllodes tumour shows broad fronds covered by bilayered epithelium, with mildly increased stromal cellularity and a hint of peri-epithelial stromal accentuation. 
can serve to identify this small subgroup of initially benign phyllodes tumours that recur with malignant histology. It has been suggested that such unanticipated behaviour could be related to the presence of unfavourable stromal subclones driving progression and recurrence, and that these changes are beyond the resolution of light microscopic recognition. ${ }^{74}$

When there is histological ambiguity however, the WHO Working Group recommends favouring a diagnosis of fibroadenoma over a benign phyllodes tumour in order to avoid overtreatment. Some authors have opted for a straddling term of benign fibroepithelial neoplasm, specifying the contentious or overlapping histological features. ${ }^{2}$

In terms of prediction of behaviour in the individual case of phyllodes tumour, the 2003 WHO edition admitted that it was difficult. ${ }^{1}$ While grade has been associated with recurrence, its assignment using conventional histological parameters is fraught with challenges in combinational permutations and interobserver variation. Some progress has been made in overcoming the uncertainty of relative weightage of histological parameters, and a predictive nomogram based on stromal atypia, mitoses, stromal overgrowth and surgical margins is believed to be able to confer a risk assessment for recurrent likelihood in the individual case, which can offer assistance in management planning and counselling. ${ }^{67}$ The real utility of this nomogram, however, needs to be validated in additional series of phyllodes tumours.

In the current WHO edition, the importance of recognising the malignant category of phyllodes tumour is emphasised. ${ }^{2}$ Malignant lesions account for between $10 \%$ and $20 \%$ of all phyllodes tumours, ${ }^{67} 69$ and is the category that is most likely to recur, with reports of up to $30 \%$ recurrence rates. In one series, ${ }^{67}$ these tumours were observed to metastasise and cause death in $22 \%$ of cases, emphasising the need for accurate diagnosis and classification to allow appropriate and timely management.

\section{CONCLUSIONS}

In conclusion, updates in the sections of myoepithelial and epithelial-myoepithelial, mesenchymal and fibroepithelial lesions as delivered in the current edition of the WHO volume of breast tumours are presented. These changes are driven by new information, shifts in understanding and approaches to lesions, practicality of application of definitions and terminologies, as well as international consensus. It is hoped that they represent a rational advance in the manner in which we classify these rarer breast tumours.

\section{Take home messages}

- In the 4th edition of WHO Classification of Tumours of the Breast, changes are proposed that reflect new information and international consensus.

- Myoepithelial carcinoma is classified with metaplastic carcinoma in recognition of the overlapping morphological and immunophenotypical characteristics.

- A panel approach should be adopted for immunohistochemical workup.

- New mesenchymal entities that are included are nodular fasciitis and atypical vascular lesions.

- It is sometimes difficult to make a clear distinction between the fibroadenoma and benign phyllodes tumour. The Working Group recommends favouring a diagnosis of fibroadenoma or using the descriptive term 'benign fibroepithelial neoplasm' in benign cases with histological ambiguity, in order to avoid overtreatment.
Acknowledgements We gratefully acknowledge the Volume Editors, participants of the WHO Consensus Conference, and authors of these chapters of the 2012 WHO Classification of Tumours of the Breast.

\section{Competing interests None.}

Provenance and peer review Commissioned; internally peer reviewed.

\section{REFERENCES}

1 Tavassoli FA, Devilee P. Pathology \& genetics. Tumours of the breast and female genital organs. Lyon, France: IARC, 2003.

2 Lakhani SR, Ellis IO, Schnitt SJ, et al. WHO classification of tumours of the breast Lyon: IARC, 2012

3 Tavassoli FA. Myoepithelial lesions of the breast. Myoepitheliosis, adenomyoepithelioma, and myoepithelial carcinoma. Am J Surg Pathol 1991;15:554-68.

4 Hayes MM. Adenomyoepithelioma of the breast: a review stressing its propensity for malignant transformation. J Clin Pathol 2011;64:477-84

5 Wells CA, Wells CW, Yeomans $P$, et al. Spherical connective tissue inclusions in epithelial hyperplasia of the breast ("collagenous spherulosis"). J Clin Pathol 1990;43:905-8

6 Resetkova E, Albarracin C, Sneige N. Collagenous spherulosis of breast: morphologic study of 59 cases and review of the literature. Am J Surg Pathol 2006:30:20-7.

7 Reis-Filho JS, Fulford LG, Crebassa B, et al. Collagenous spherulosis in an adenomyoepithelioma of the breast. J Clin Pathol 2004;57:83-6.

8 Rabban JT, Swain RS, Zaloudek CJ, et al. Immunophenotypic overlap between adenoid cystic carcinoma and collagenous spherulosis of the breast: potential diagnostic pitfalls using myoepithelial markers. Mod Pathol 2006;19:1351-7.

9 Ogata K, Sakamoto G, Sakurai T. Adenoid cystic carcinoma with collagenous spherulosis-like structures in the breast: report of a case. Pathol Int 2004;54:332-6.

10 Mooney EE, Kayani N, Tavassoli FA. Spherulosis of the breast. A spectrum of municous and collagenous lesions. Arch Pathol Lab Med 1999;123:626-30.

11 Guarino M, Tricomi P, Cristofori E. Collagenous spherulosis of the breast with atypical epithelial hyperplasia. Pathologica 1993;85:123-7.

12 Grignon DJ, Ro JY, Mackay BN, et al. Collagenous spherulosis of the breast. Immunohistochemical and ultrastructural studies. Am J Clin Pathol 1989;91:386-92.

13 Clement PB, Young RH, Azzopardi JG. Collagenous spherulosis of the breast. Am J Surg Pathol 1987;11:411-17.

14 Schurch W, Potvin C, Seemayer TA. Malignant myoepithelioma (myoepithelial carcinoma) of the breast: an ultrastructural and immunocytochemical study. Ultrastruct Pathol 1985;8:1-11.

15 Lakhani SR, O'Hare MJ, Monaghan P, et al. Malignant myoepithelioma (myoepithelial carcinoma) of the breast: a detailed cytokeratin study. J Clin Pathol 1995:48:164-7

16 Chen PC, Chen CK, Nicastri AD, et al. Myoepithelial carcinoma of the breast with distant metastasis and accompanied by adenomyoepitheliomas. Histopathology 1994;24:543-8

17 Coyne JD, Dervan PA, Barr L. High-grade carcinomas of the breast showing patterns of mixed ductal and myoepithelial differentiation (including myoepithelial cell-rich carcinoma of the breast). Histopathology 2004;44:580-4.

18 Buza N, Zekry N, Charpin C, et al. Myoepithelial carcinoma of the breast: a clinicopathological and immunohistochemical study of 15 diagnostically challenging cases. Virchows Arch 2010;457:337-45.

19 Jones C, Nonni AV, Fulford L, et al. CGH analysis of ductal carcinoma of the breast with basaloid/myoepithelial cell differentiation. Br J Cancer 2001;85:422-7.

20 Behranwala KA, Nasiri N, A'Hern R, et al. Clinical presentation and long-term outcome of pure myoepithelial carcinoma of the breast. Eur I Surg Oncol 2004;30:357-61

21 Yigit S, Pehlivan FS, Evcim G, et al. Clinicopathologic features of the mixed epithelial and mesenchymal type metaplastic breast carcinoma with myoepithelial differentiation in a subset of six cases. Pathol Res Pract 2012;208:147-50.

22 Han B, Mori I, Nakamura M, et al. Myoepithelial carcinoma arising in an adenomyoepithelioma of the breast: case report with immunohistochemical and mutational analysis. Pathol Int 2006;56:211-16.

23 Diaz NM, McDivitt RW, Wick MR. Pleomorphic adenoma of the breast: a clinicopathologic and immunohistochemical study of 10 cases. Hum Pathol 1991;22:1206-14.

24 Ballance WA, Ro JY, el-Naggar AK, et al. Pleomorphic adenoma (benign mixed tumor) of the breast. An immunohistochemical, flow cytometric, and ultrastructural study and review of the literature. Am J Clin Pathol 1990;93:795-801.

25 Rosen PP. Adenomyoepithelioma of the breast. Hum Pathol 1987;18:1232-7.

26 Young RH, Clement PB. Adenomyoepithelioma of the breast. A report of three cases and review of the literature. Am J Clin Pathol 1988;89:308-14.

27 Jabi M, Dardick I, Cardigos N. Adenomyoepithelioma of the breast. Arch Pathol Lab Med 1988:112:73-6. 
28 McLaren BK, Smith J, Schuyler PA, et al. Adenomyoepithelioma: clinical, histologic, and immunohistologic evaluation of a series of related lesions. Am J Surg Pathol 2005:29:1294-9.

29 Cai RZ, Tan PH. Adenomyoepithelioma of the breast with squamous and sebaceous metaplasia. Pathology 2005:37:557-9.

30 Loh HL, Kumarasinghe P, Tan PH. Test and Teach. Recurrent breast lumps in a Chinese woman. Adenomyoepithelioma of the breast. Pathology 2004;36:269-72.

31 Jones C, Tooze R, Lakhani SR. Malignant adenomyoepithelioma of the breast metastasizing to the liver. Virchows Arch 2003;442:504-6

32 Ahmed AA, Heller DS. Malignant adenomyoepithelioma of the breast with malignant proliferation of epithelial and myoepithelial elements: a case report and review of the literature. Arch Pathol Lab Med 2000;124:632-6.

33 Simpson RH, Cope N, Skalova A, et al. Malignant adenomyoepithelioma of the breast with mixed osteogenic, spindle cell, and carcinomatous differentiation. Am J Surg Pathol 1998;22:631-6.

34 Rasbridge SA, Millis RR. Adenomyoepithelioma of the breast with malignant features. Virchows Arch 1998;432:123-30.

35 Michal M, Baumruk L, Burger J, et al. Adenomyoepithelioma of the breast with undifferentiated carcinoma component. Histopathology 1994;24:274-6.

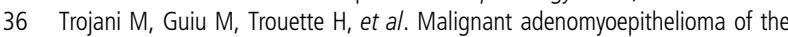
breast. An immunohistochemical, cytophotometric, and ultrastructural study of a case with lung metastases. Am J Clin Pathol 1992;98:598-602.

37 Loose JH, Patchefsky AS, Hollander IJ, et al. Adenomyoepithelioma of the breast. A spectrum of biologic behavior. Am J Surg Pathol 1992;16:868-76.

38 Vranic S, Bender R, Palazzo J, et al. A review of adenoid cystic carcinoma of the breast with emphasis on its molecular and genetic characteristics. Hum Pathol 2013;44:301-9.

39 Trendell-Smith NJ, Peston D, Shousha S. Adenoid cystic carcinoma of the breast: a tumour commonly devoid of oestrogen receptors and related proteins. Histopathology 1999;35:241-8.

40 Soon SR, Yong WS, Ho GH, et al. Adenoid cystic breast carcinoma: a salivary gland-type tumour with excellent prognosis and implications for management. Pathology 2008;40:413-15.

41 Rosen PP. Adenoid cystic carcinoma of the breast. A morphologically heterogeneous neoplasm. Pathol Annu 1989;(24 Pt 2):237-54.

42 Page DL. Adenoid cystic carcinoma of breast, a special histopathologic type with excellent prognosis. Breast Cancer Res Treat 2005;93:189-90.

43 Mastropasqua MG, Maiorano E, Pruneri G, et al. Immunoreactivity for c-kit and p63 as an adjunct in the diagnosis of adenoid cystic carcinoma of the breast. Mod Pathol 2005;18:1277-82.

44 Kasami M, Olson SJ, Simpson JF, et al. Maintenance of polarity and a dual cell population in adenoid cystic carcinoma of the breast: an immunohistochemical study. Histopathology 1998:32:232-8

45 Gillett CE, Bobrow LG, Millis RR. S100 protein in human mammary tissue -immunoreactivity in breast carcinoma, including Paget's disease of the nipple, and value as a marker of myoepithelial cells. J Pathol 1990;160:19-24.

46 Joshi MG, Lee AK, Pedersen CA, et al. The role of immunocytochemical markers in the differential diagnosis of proliferative and neoplastic lesions of the breast. Mod Pathol 1996;9:57-62

47 Tramm T, Kim JY, Tavassoli FA. Diminished number or complete loss of myoepithelial cells associated with metaplastic and neoplastic apocrine lesions of the breast. Am J Surg Pathol 2011:35:202-11.

48 Hilson JB, Schnitt SJ, Collins LC. Phenotypic alterations in myoepithelial cells associated with benign sclerosing lesions of the breast. Am J Surg Pathol 2010;34:896-900.

49 Hilson JB, Schnitt SJ, Collins LC. Phenotypic alterations in ductal carcinoma in situ-associated myoepithelial cells: biologic and diagnostic implications. Am J Surg Pathol 2009:33:227-32.

50 Dewar $\mathrm{R}$, Fadare 0 , Gilmore $\mathrm{H}$, et al. Best practices in diagnostic immunohistochemistry: myoepithelial markers in breast pathology. Arch Pathol Lab Med 2011:135:422-9.
51 Moriya T, Kozuka Y, Kanomata N, et al. The role of immunohistochemistry in the differential diagnosis of breast lesions. Pathology 2009;41:68-76.

52 Tan PH, Aw MY, Yip G, et al. Cytokeratins in papillary lesions of the breast: is there a role in distinguishing intraductal papilloma from papillary ductal carcinoma in situ? Am J Surg Pathol 2005;29:625-32.

53 Carter MR, Hornick JL, Lester S, et al. Spindle cell (sarcomatoid) carcinoma of the breast: a clinicopathologic and immunohistochemical analysis of 29 cases. Am J Surg Pathol 2006;30:300-9.

54 Dunne B, Lee AH, Pinder SE, et al. An immunohistochemical study of metaplastic spindle cell carcinoma, phyllodes tumor and fibromatosis of the breast. Hum Pathol 2003;34:1009-15

55 Dahlstrom J, Buckingham J, Bell S, et al. Nodular fasciitis of the breast simulating breast cancer on imaging. Australas Radiol 2001;45:67-70.

56 Birdsall SH, Shipley JM, Summersgill BM, et al. Cytogenetic findings in a case of nodular fasciitis of the breast. Cancer Genet Cytogenet 1995;81:166-8.

57 Koizumi $\mathrm{H}$, Mikami M, Doi $\mathrm{M}$, et al. Clonality analysis of nodular fasciitis by HUMARA-methylation-specific PCR. Histopathology 2005;47:320-1.

58 Erickson-Johnson MR, Chou MM, Evers BR, et al. Nodular fasciitis: a novel model of transient neoplasia induced by MYH9-USP6 gene fusion. Lab Invest 2011;91:1427-33.

59 Hartel PH, Bratthauer G, Hartel JV, et al. Primary malignant fibrous histiocytoma (myxofibrosarcoma/pleomorphic sarcoma not otherwise specified) of the breast: clinicopathologic study of 19 cases. Ann Diagn Pathol 2011;15:407-13.

60 Mandrell J, Mehta S, McClure S. Atypical vascular lesion of the breast. J Am Acad Dermatol 2010:63:337-40.

61 Lucas DR. Angiosarcoma, radiation-associated angiosarcoma, and atypical vascular lesion. Arch Pathol Lab Med 2009:133:1804-9.

62 Brodie C, Provenzano E. Vascular proliferations of the breast. Histopathology 2008;52:30-44.

63 Patton KT, Deyrup AT, Weiss SW. Atypical vascular lesions after surgery and radiation of the breast: a clinicopathologic study of 32 cases analyzing histologic heterogeneity and association with angiosarcoma. Am J Surg Pathol 2008;32:943-50.

64 Tavassoli FA, Weiss S. Hemangiopericytoma of the breast. Am J Surg Pathol 1981:5:745-52.

65 Magro G, Fraggetta F, Torrisi A, et al. Myofibroblastoma of the breast with hemangiopericytoma-like pattern and pleomorphic lipoma-like areas. Report of a case with diagnostic and histogenetic considerations. Pathol Res Pract 1999:195:257-62.

66 Nascimento AF, Raut CP, Fletcher CD. Primary angiosarcoma of the breast: clinicopathologic analysis of 49 cases, suggesting that grade is not prognostic. Am J Surg Pathol 2008;32:1896-904.

67 Tan PH, Thike AA, Tan WJ, et al. Predicting clinical behaviour of breast phyllodes tumours: a nomogram based on histological criteria and surgical margins. J Clin Pathol 2012:65:69-76.

68 Giri D. Recurrent challenges in the evaluation of fibroepithelial lesions. Arch Pathol Lab Med 2009;133:713-21.

69 Tan PH, Jayabaskar T, Chuah KL, et al. Phyllodes tumors of the breast: the role of pathologic parameters. Am J Clin Pathol 2005;123:529-40.

70 Grady I, Gorsuch H, Wilburn-Bailey S. Long-term outcome of benign fibroadenomas treated by ultrasound-guided percutaneous excision. Breast J 2008;14:275-8.

71 Nigro DM, Organ CH Jr. Fibroadenoma of the female breast. Some epidemiologic surprises. Postgrad Med 1976;59:113-17.

72 Organ CH Jr, Organ BC. Fibroadenoma of the female breast: a critical clinical assessment. J Natl Med Assoc 1983;75:701-4.

73 Barth RJ Jr. Histologic features predict local recurrence after breast conserving therapy of phyllodes tumors. Breast Cancer Res Treat 1999;57:291-5.

74 Jones AM, Mitter $\mathrm{R}$, Springall $\mathrm{R}$, et al. A comprehensive genetic profile of phyllodes tumours of the breast detects important mutations, intra-tumoral genetic heterogeneity and new genetic changes on recurrence. J Pathol 2008:214:533-44. 